\title{
TEMPERATURA APARENTE DE SUPERFÍCIE NA BACIA HIDROGRÁFICA DO RIO TAVARES, FLORIANÓPOLIS
}

\author{
RODRIGUES, Marcelo - gr4fitt3@gmail.com \\ Universidade Federal de Itajubá / UNIFEI \\ DUPAS, Francisco Antônio - dupas@unifei.edu.br \\ Universidade Federal de Itajubá / UNIFEI \\ REBOITA, Michelle Simões - reboita@unifei.edu.br \\ Universidade Federal de Itajubá / UNIFEI
}

\begin{abstract}
RESUMO: Tendo em vista a rápida urbanização durante as duas últimas décadas da cidade de Florianópolis (SC), o objetivo do estudo foi analisar as variações nas características de temperatura aparente da superfície (Tas) obtidas via procedimentos matemáticos a partir de imagens do satélite Landsat $5 \mathrm{TM}$, para a região da Bacia Hidrográfica do Rio Tavares, em decorrência das modificações em superfície impostas pelo desenvolvimento urbano da região ao longo das décadas de 1990 e 2000. Os resultados obtidos indicaram que a bacia apresentou uma diminuição nas áreas dominadas pelas classes de Mata Atlântica, solo exposto ou vegetação rasteira e corpos hídricos, como consequência da expansão das atividades e áreas urbanas. Este estudo concluiu que as porções da bacia que apresentaram maior Tas estão associadas a áreas de maior urbanização e ausência de vegetação expressiva, demonstrando a influência das características dos materiais que recobrem a superfície no balanço de calor do meio físico.
\end{abstract}

Palavras- chaves: Temperatura aparente de superfície; Uso e ocupação do solo; Desenvolvimento urbano; Sensoriamento remoto

\section{APPARENT SURFACE TEMPERATURE OVER THE RIO TAVARES BASIN, FLORIANÓPOLIS}

ABSTRACT: Given the fast urbanization in the last two decades of the Florianópolis city (SC), the main objective of this study was to analyze the variations in apparent surface temperature characteristics (Tas) obtained via mathematical procedures from the satellite Landsat 5 TM images, for the region of Rio Tavares Basin, with the changes in surface due the urban development over the 1990's and 2000's decades. The results indicated that the basin showed a decrease in areas dominated by the Atlantic Forest, exposed soil or low vegetation and water bodies classes, as result of expansion of the activities and urban areas. This study concluded that the portions of the basin that had higher Tas are associated with areas of increased urbanization and significant vegetation lack, demonstrating the influence of the material characteristics that cover the surface in the environmental heat balance.

Keywords: Apparent surface temperature; Urban climate; Land use and occupation; Urban growth. Remote sensing.

\section{INTRODUÇÃO}

A problemática da urbanização, tendo em vista o seu avanço crescente e frequentemente desordenado, tem feito parte marcante no processo de discussão das políticas públicas e ambientais das grandes cidades, principalmente a partir da segunda metade do século $X X$ e de maneira mais intensa no início do século atual. 
Através da expansão espacial das cidades e o aumento da concentração urbana, a modificação da paisagem natural acontece invariavelmente, levando, por consequência, à alteração nos componentes e processos físicos, químicos e biológicos característicos do ambiente.

Segundo Lombardo (1985), as alterações na superfície terrestre decorrentes do crescimento e adensamento populacional, do aumento de construções urbanas de médio e grande porte às custas da supressão da vegetação natural e dos corpos hídricos, acabam por promover significativas mudanças nas características atmosféricas, alterando o balanço de calor em superfície e definindo o clima urbano. Estudos têm demonstrado que o aumento nos fluxos de calor sensível e modificações na rugosidade das áreas urbanizadas, provocados por tais mudanças no uso e ocupação do solo, são fatores que favorecem o desenvolvimento de ilhas de calor e alteram as características do vento atuante (SILVA DIAS et al., 2013)

A interação entre as caraterísticas naturais da atmosfera local e o ambiente urbano proposto e criado pelo homem define os microclimas das cidades (AMORIM, 2000). Entre outras consequências desta interface sobre o clima urbano pode-se destacar: alterações dos extremos e médias de temperatura do ar e de superfície; o surgimento de ilhas de calor; modificações no regime de precipitação e na umidade relativa do ar; assim como o aumento da concentração de compostos poluentes na baixa atmosfera (ORTIZ; AMORIM, 2012).

Com o avanço das técnicas de sensoriamento remoto, análises do clima urbano por imagens de satélite são cada vez mais frequentes (CARLSON et al., 1977; MATSON et al., 1978; ROTH et al., 1989; LIMA; AMORIM, 2010; LUCENA et al., 2013; RIOS et al., 2014). O uso de bandas de satélite no infravermelho termal permite captar a energia eletromagnética de quaisquer objetos com temperatura acima do zero absoluto. Desse modo, todos os elementos de uma paisagem, seja urbana ou natural, podem ser retratados em uma imagem de satélite por meio da sua energia termal emitida (WENG; YANG, 2004; DASH et al., 2002; JENSEN, 2009).

Um dos primeiros trabalhos relacionando o uso do sensoriamento remoto na faixa do infravermelho termal para a estimação dos microclimas urbanos, mais especificamente avaliando a presença de ilhas de calor, foi realizado por Rao (1972) para a região compreendida entre as cidades de Washington e Nova York, costa leste dos Estados Unidos, dando início ao aprofundamento científico no tema.

Kalnay e Cai (2003) avaliaram a influência das áreas urbanas e da mudança no uso e ocupação do solo sobre o clima comparando as tendências observadas de temperatura de superfície em cidades dos Estados Unidos com àquelas levantadas por dados de reanálise dos últimos 60 anos. Dessa forma, os autores estimaram o impacto das mudanças no uso e ocupação do solo sobre o aquecimento de superfície e mostraram que metade da diminuição da variação de temperatura diurna observada foi devido aos processos de urbanização.

Um estudo similar produzido por Yang et al. (2009) em território chinês demonstrou que o aquecimento de superfície apresentava ritmos de evolução diferentes dependendo do tipo de cobertura do solo. Por meio da subtração de dados de reanálise de temperatura de superfície em relação aos dados de 
observação, concluiu-se que a taxa de aumento da temperatura superficial por década é maior em zonas áridas e com baixa concentração de vegetação, enquanto que as menores taxas ocorrem preferencialmente em regiões densamente florestadas.

Lucena et al. (2013) mapearam a região metropolitana do Rio de Janeiro em relação à temperatura de superfície no período de inverno e à presença de ilhas de calor influenciadas pelo uso e ocupação do solo para as décadas de 1980, 1990 e 2000, utilizando a banda do infravermelho termal do satélite Landsat 5 TM. Os resultados encontrados mostraram uma distribuição da temperatura homogênea ao longo das décadas, onde áreas urbanas apresentaram as maiores temperaturas, seguidas das zonas de transição representadas pelas áreas rurais. Parcelas do território com maior porcentagem de vegetação corroboraram com os estudos anteriores levantados, apresentando menores valores de temperatura aparente de superfície.

Neste contexto, um conjunto de dados envolvendo a temperatura aparente de superfície emitida por uma área somado com informações sobre o uso e ocupação do solo permitem criar uma base relevante de auxílio no estudo da qualidade socioambiental de uma região, representando uma importante ferramenta de gestão urbana para o poder público.

Tendo em vista a rápida urbanização durante as duas últimas décadas da cidade de Florianópolis (SC), o objetivo do presente trabalho foi relacionar as variações espaciais e temporais da temperatura aparente de superfície (Tas) para a Bacia Hidrográfica do Rio Tavares com as modificações em superfície impostas pelo crescimento populacional e desenvolvimento urbano da região, ao longo das décadas de 1990 e 2000. A Tas foi estimada através de um método matemático que converte a radiância espectral da superfície terrestre e atmosfera, obtida pelo sensor do satélite, em temperatura aparente. Dessa forma, procura-se oferecer subsídios para a compreensão da dinâmica microclimática em função do meio antrópico na qual se insere, por meio de técnicas de sensoriamento remoto.

\section{2. ÁREA DE ESTUDO}

A Ilha de Santa Catarina está geograficamente inserida entre as latitudes $27^{\circ} 22 \mathrm{~S}$ e $27^{\circ} 50^{\prime} \mathrm{S}$ e as longitudes $48^{\circ} 20^{\prime} \mathrm{O}$ e $48^{\circ} 35^{\prime} \mathrm{O}$, fazendo parte do município de Florianópolis. Disposta no sentido nordeste-sudoeste, a ilha apresenta uma área aproximada de $425 \mathrm{~km}^{2}$ e $172 \mathrm{~km}$ de perímetro costeiro. Segundo dados do IBGE (2013), o município de Florianópolis compreende uma população de 453.285 habitantes.

Bastante conhecida por suas praias, a Ilha abriga uma diversidade de ecossistemas costeiros, envolvendo desde costões rochosos, manguezais, lagunas, praias, até extensas áreas de dunas e restingas (HORN FILHO, 2006).

Um estudo compreendendo dados coletados entre os anos de 1961 e 1970 mostrou que a temperatura média anual para a região de Florianópolis é de cerca de $20^{\circ} \mathrm{C}$, com variações mensais de $13^{\circ} \mathrm{C}$ e $26^{\circ} \mathrm{C}$ dependendo da estação do ano (GOULART, 1993; ANDRADE, 1996). Em relação ao regime de ventos, há uma predominância de ventos provindos de quadrante norte e nordeste, com uma menor contribuição, porém de maior intensidade, de ventos 
de sudeste e sul (MONTEIRO, 1995; MENDONÇA, 2002), quando há passagem de frentes frias pela região. É importante salientar que as informações da climatologia de ventos mencionadas correspondem a um conjunto de dados referentes ao período de 1951-1970.

Por fim, o Instituto Nacional de Meteorologia (INMET) informa que, entre 1925 e 1995, a média anual dos totais de precipitação em Florianópolis é de aproximadamente $1500 \mathrm{~mm}$, onde cerca de $35 \%$ do total ocorre durante a estação de verão, $25 \%$ na primavera, $20 \%$ no outono e outros $20 \%$ durante a estação de inverno (MENDONÇA, 2002).

\subsection{BACIA HIDROGRÁFICA DO RIO TAVARES}

Localizada no setor centro-sul da Ilha de Santa Catarina, a Bacia Hidrográfica do Rio Tavares possui uma área de aproximadamente $48,36 \mathrm{~km}^{2}$ (ARAUJO, 1993), perfazendo cerca de $11 \%$ da área total compreendida pela ilha (Figura 1).

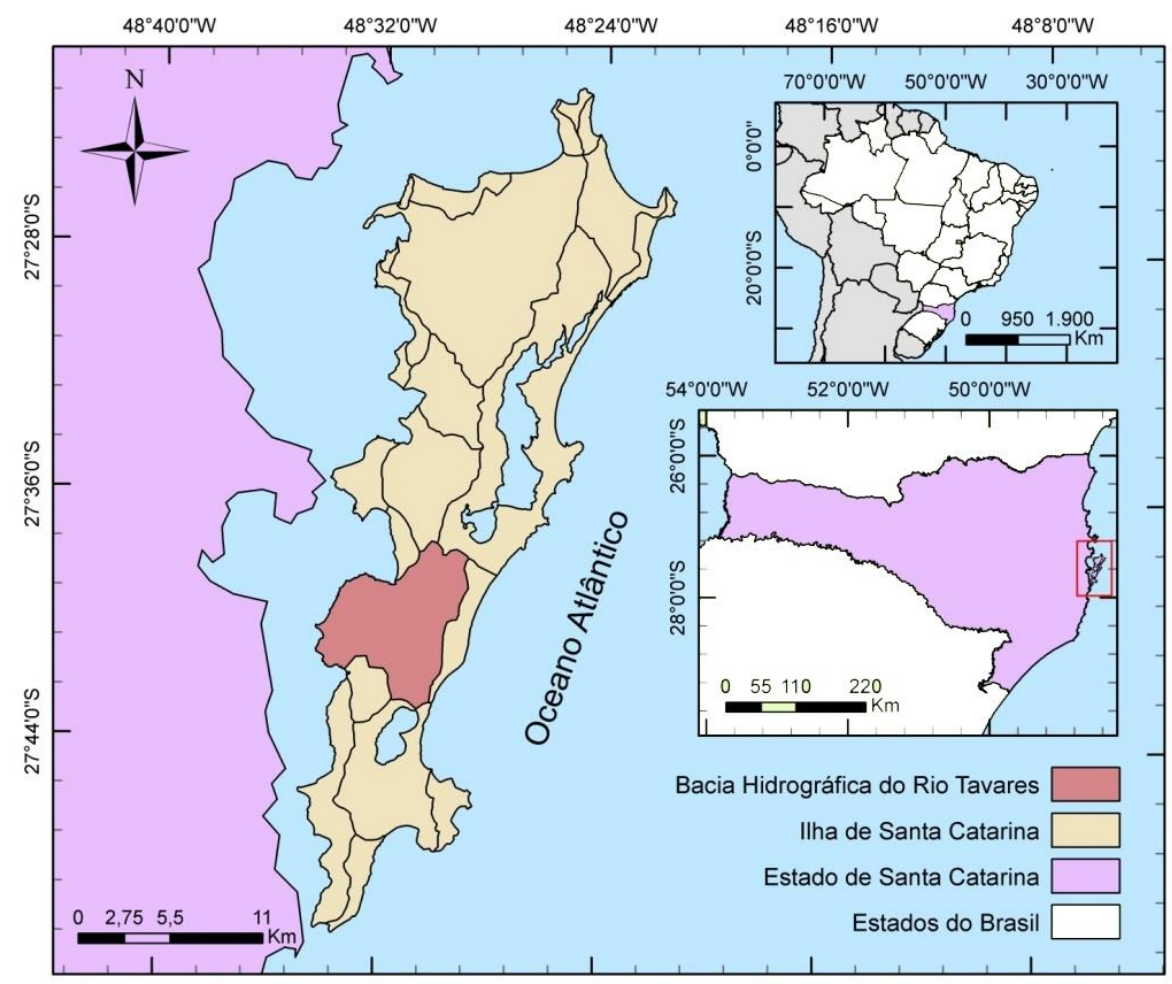

Figura 1 - A Ilha de Santa Catarina e a Bacia Hidrográfica do Rio Tavares.

A bacia tem como seu principal curso d'água, o rio Tavares, com um comprimento de aproximadamente $7 \mathrm{~km}$ e com desague nas águas da Baía Sul, a oeste da Ilha de Santa Catarina (SCHETTINI et al., 2000). A maior parte da hidrografia da bacia se espalha ao longo de terrenos cuja altitude não ultrapassa 15 metros (Figura 2). 


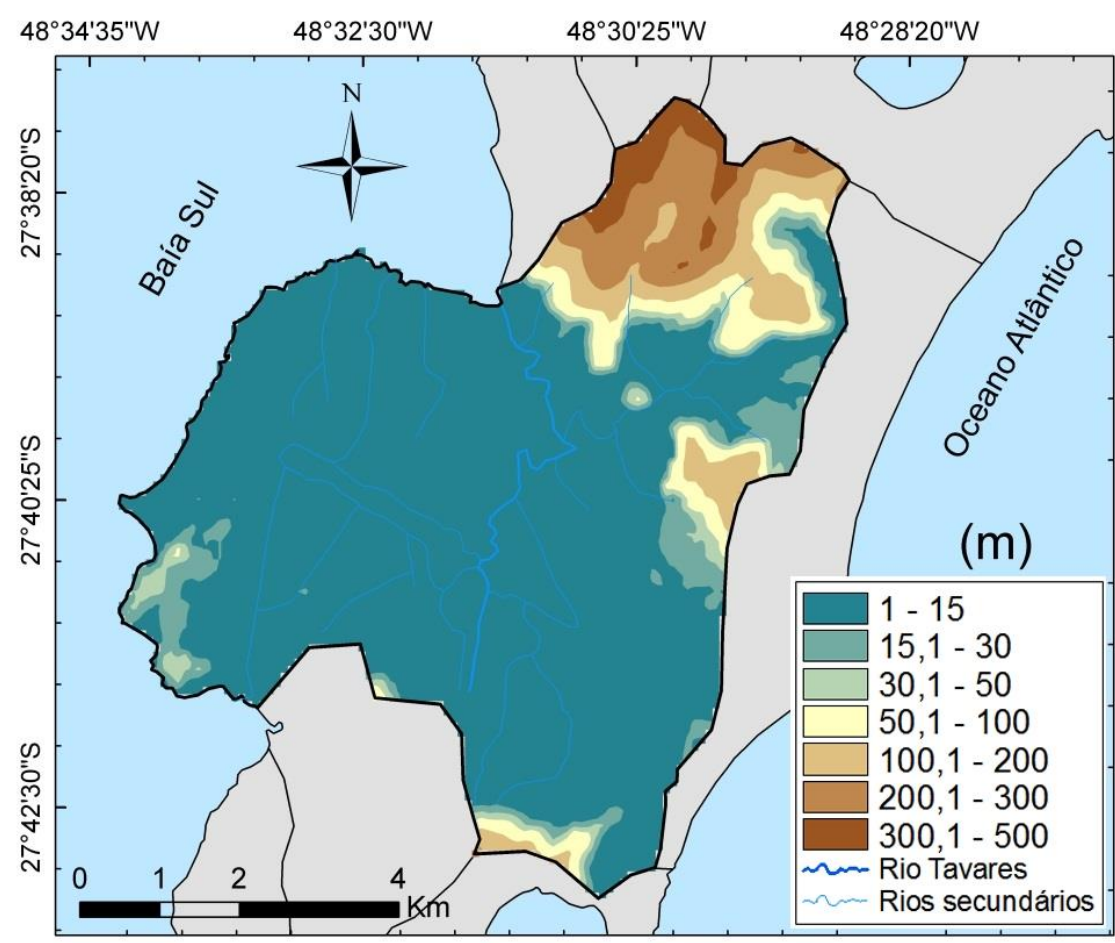

Figura 2 - Hipsometria, em metros, da Bacia Hidrográfica do Rio Tavares. Fonte dos dados: obtidos através do modelo digital de elevação (carta SG-22-Z-D) disponibilizado pela Empresa Brasileira de Pesquisa Agropecuária (EMBRAPA).

Segundo Trevisan, Santos e Luiz (2013), a Bacia Hidrográfica do Rio Tavares apresenta população residente de aproximadamente 40 mil habitantes, correspondendo a quase $10 \%$ da população total do município de Florianópolis.

\section{MATERIAL E MÉTODOS}

\subsection{IMAGENS DE SATÉLITE UTILIZADAS}

Foram obtidas 22 imagens do sensor TM (Thematic Mapper; Tabela 1), instalado no satélite Landsat 5, cuja frequência de passagem pela mesma área é de 16 dias. Tais imagens foram selecionadas através do catálogo virtual disponibilizado pela Divisão de Geração de Imagens (DGI), do Instituto Nacional de Pesquisas Espaciais (INPE), cuja função engloba a recepção, o processamento e a distribuição de imagens de satélite. Para este estudo, foram priorizadas as imagens com menor porcentagem disponível de cobertura de nuvens para a área de estudo, no intuito de diminuir qualquer interferência nesse sentido. Todas as imagens selecionadas apresentaram uma porcentagem menor que $10 \%$ de cobertura de nuvens ao longo de toda a área da imagem, sendo que, em nenhuma delas as nuvens se posicionaram sobre a área de estudo diretamente.

Todas as imagens estão situadas na órbita/ponto 220/079 e são relativas à estação de inverno das décadas de 1990 e 2000 . O uso unicamente dos dados 
da estação de inverno se deve à maior disponibilidade de imagens com baixa cobertura de nuvens, quando comparada com as demais estações. Procurou-se selecionar as imagens de forma bem distribuída ao longo do inverno de cada década, conforme a disponibilidade de uso. Além disso, também se teve a preocupação de excluir períodos com atividades frontais (pré a pós frontais), que podem influenciar na temperatura obtida por meio das imagens

Tabela 1 - Data e hora das imagens do satélite Landsat 5 TM utilizadas, compreendendo as décadas de 1990 e 2000.

\begin{tabular}{ccc}
\hline Data & Hora \\
\hline $\mathbf{0 7 / 0 7 / 1 9 9 0}$ & $12: 31: 51$ \\
\hline $\mathbf{1 2} / 09 / \mathbf{1 9 9 1}$ & $12: 35: 35$ \\
\hline $\mathbf{1 5} / 07 / 1993$ & $12: 34: 07$ \\
$\mathbf{1 8 / 0 7 / 1 9 9 4}$ & $12: 29: 46$ \\
\hline $\mathbf{0 3 / 0 8 / 1 9 9 4}$ & $12: 29: 19$ \\
$\mathbf{0 3 / 0 6 / 1 9 9 5}$ & $12: 18: 27$ \\
$\mathbf{2 4 / 0 6 / 1 9 9 7}$ & $12: 41: 29$ \\
$\mathbf{3 0 / 0 8 / 1 9 9 8}$ & $12: 50: 22$ \\
$\mathbf{3 0 / 0 6 / 1 9 9 9}$ & $12: 49: 29$ \\
$\mathbf{0 1 / 0 8 / 1 9 9 9}$ & $12: 49: 27$ \\
& $\mathbf{1 9 / 0 8 / 2 0 0 0}$ & \\
$\mathbf{1 1 / 0 7 / 2 0 0 3}$ & $12: 49: 25$ \\
$\mathbf{1 2 / 0 8 / 2 0 0 3}$ & $12: 48: 04$ \\
$\mathbf{3 0 / 0 8 / 2 0 0 4}$ & $12: 48: 37$ \\
$\mathbf{0 1 / 0 8 / 2 0 0 5}$ & $12: 55: 08$ \\
$\mathbf{0 2 / 0 9 / 2 0 0 5}$ & $12: 59: 40$ \\
$\mathbf{0 1 / 0 6 / 2 0 0 6}$ & $12: 59: 51$ \\
$\mathbf{2 0 / 0 8 / 2 0 0 6}$ & $13: 04: 06$ \\
$\mathbf{0 5 / 0 9 / 2 0 0 6}$ & $13: 05: 13$ \\
$\mathbf{0 4 / 0 6 / 2 0 0 7}$ & $13: 05: 24$ \\
$\mathbf{2 3 / 0 8 / 2 0 0 7}$ & $13: 05: 58$ \\
$\mathbf{2 8 / 0 8 / 2 0 0 9}$ & $13: 05: 01$ \\
\hline & $13: 01: 14$ \\
\hline
\end{tabular}

\subsection{PROCEDIMENTOS}

A partir das imagens do sensor TM, determinou-se a média decadal (1990-1999 e 2000-2009) para a temperatura de superfície, sendo que 10 imagens foram utilizadas para compor a média da década de 1990, e 12 imagens para a média da década de 2000. Para tais cálculos foi utilizado a função Raster Calculator do software ArcMap 10.1, que possibilita o cálculo das médias a partir dos pixels das imagens de cada década.

O georreferenciamento de cada uma das imagens foi realizado no software ArcMap 10.1, tendo como referência 10 coordenadas de pontos 
conhecidos entre as imagens de satélite e a carta topográfica de Florianópolis, produzida pelo Instituto Brasileiro de Geografia e Estatística (IBGE) no ano de 1983, com escala de 1:50000.

\subsubsection{CLASSIFICAÇÃO DO USO E COBERTURA DO SOLO}

Foram criadas cinco assinaturas espectrais para as categorias definidas na classificação do uso e cobertura do solo, que foram: área urbana; vegetação de Mata Atlântica; solo exposto ou vegetação rasteira; manguezal; e corpos hídricos. As diversas classes quanto ao uso e cobertura do solo foram definidas com base em conhecimento prévio da área de estudo e pelas médias das imagens de satélite para cada década.

A partir das assinaturas, o software ArcMap 10.1 associa o valor de cada pixel da imagem à assinatura espectral mais semelhante. O processo é denominado classificação supervisionada por máxima verossimilhança e foi realizado para ambas as décadas analisadas.

\subsubsection{EXTRAÇÃO DA TEMPERATURA APARENTE DE SUPERFÍCIE}

A obtenção da temperatura real de um corpo em superfície a partir de imagens de satélite envolve considerar a compensação da emissividade, que é a razão entre a quantidade de energia emitida por um corpo real sob uma dada temperatura e a quantidade de energia emitida pelo corpo negro nessa mesma temperatura. Ainda, é preciso levar em consideração os processos de atenuação e transmitância da energia eletromagnética pelas camadas da atmosfera, que também são captados pelo sensor do satélite.

No entanto, conforme argumenta Souza e Silva (2005), dentro da janela atmosférica onde o canal do infravermelho termal do satélite Landsat 5 TM atua, compreendida no intervalo de $8 \mu \mathrm{m}$ a $12 \mu \mathrm{m}$, a atenuação da radiação incidente e emitida pela superfície ao longo da atmosfera é de baixa intensidade. Nesse caso, as moléculas de vapor d'água induzem a maior parte do processo de atenuação, em comparação com gases e aerossóis de atuação desprezíveis neste intervalo espectral (SOUZA; SILVA, 2005). Assim, em virtude de tais considerações e também pela dificuldade metodológica que envolve os procedimentos para uma correção dos efeitos atmosféricos adequados, foi considerada neste estudo apenas a emissividade em superfície.

Por fim, os processos para obtenção das Tas envolveram 22 imagens do infravermelho termal do satélite (banda 6). As datas de todas as imagens correspondem ao período de inverno e o horário de passagem do satélite sobre a área de estudo compreendeu o período entre 12:15 e 13:05 UTC (Coordinated Universal Time).

Primeiramente, os valores dos níveis de cinza de cada uma das duas médias decadais (1990-1999 e 2000-2009) foram transformados para radiância espectral, a partir de metodologia discutida por Chander, Markham e Helder (2009), na qual se utiliza a Equação 1:.

$$
L \lambda i=\frac{L M A X i-L M I N i}{Q C A L M A X-Q C A L M I N}(Q C A L-Q C A L M I N)+L M I N i
$$


onde:

i - bandas do sensor TM acoplado no satélite Landsat 5 (banda 3, 4, 5, 6)

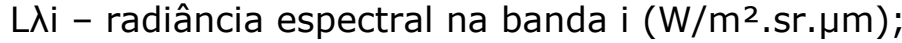

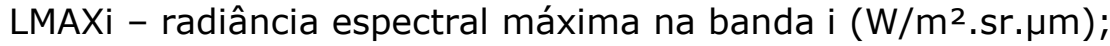

LMINi - radiância espectral mínima na banda i $\left(\mathrm{W} / \mathrm{m}^{2} . \mathrm{sr} . \mu \mathrm{m}\right)$;

QCAL - radiância calibrada para o intervalo 0 a 255;

QCALMAX - valor digital máximo da imagem;

QCALMIN - valor digital mínimo da imagem.

A reflectância monocromática ao nível do satélite nas bandas 3 e 4 foram obtidas através da Equação 2:

onde:

$$
\rho i=\frac{\pi L i d^{2}}{E S U N i \cos (\theta s)}
$$

i - bandas do sensor TM acoplado no satélite Landsat 5 (bandas 3 e 4)

$\mathrm{Li}$ - radiância espectral na banda i (W/m².sr. $\mu \mathrm{m})$;

d - distância Terra-Sol na ocasião da cena em medidas astronômicas (UA);

ESUNi - irradiância solar média no topo da atmosfera de cada banda $\left(\mathrm{W} / \mathrm{m}^{2} \cdot \mu \mathrm{m}\right)$;

Os - ângulo solar zenital em graus no momento da obtenção da imagem pelo satélite.

O cálculo da Tas é obtido através da equação de Planck invertida (SOUZA; SILVA, 2005), sendo aplicável para a extração de temperatura de corpos negros. Uma vez que as diferentes superfícies se comportam diferentemente à radiação incidente, é preciso levar em consideração a emissividade dos diferentes pixels da imagem na banda termal, relativos aos diferentes tipos de superfície e ocupação do solo. De acordo com o algoritmo apresentado por Allen et al. (2007), a emissividade da superfície é obtida através de uma relação com o Índice de Área Foliar (IAF), dada pela equação:

$$
\varepsilon=0,97+0,00331 I A F
$$

A equação acima é aplicada quando o Índice de Vegetação por Diferença Normalizada (NDVI) for maior que zero (NDVI > 0), indicando a presença de solo ou vegetação, e quando IAF $<3$. Do contrário se utiliza $\varepsilon=0,98$ quando IAF > 3, e $\varepsilon=0,985$ quando NDVI < 0 (ALLEN et al., 2007).

O NDVI é dado pela razão da diferença entre a reflectância da banda do infravermelho próximo ( $\rho 4)$ e a reflectância da banda do vermelho ( $\rho 3)$, e a soma entre estas (Equação 4). 


$$
N D V I=\frac{(\rho 4-\rho 3)}{(\rho 4+\rho 3)}
$$

Para a estimativa do IAF é necessário conhecer o Índice de Vegetação Ajustado ao Solo (SAVI), cujo objetivo é diminuir os efeitos de background do solo (HUETE, 1988). Tal índice é dado pela equação:

$$
S A V I=\frac{(1+L)(\rho 4-\rho 3)}{L+(\rho 4+\rho 3)}
$$

onde:

$\mathrm{L}$ - constante dependente do tipo de solo, comumente utilizado um valor de 0,5 (MOREIRA, 2009);

p3 - reflectância da banda do vermelho (banda 3);

p4 - reflectância do infravermelho próximo (banda 4).

A equação para a obtenção do IAF é dada por:

$$
I A F=-\frac{\ln \left(\frac{0,69-S A V I}{0,59}\right)}{0,91}
$$

Por fim, a Tas em Kelvin (K) é obtida através de uma equação que relaciona a radiância espectral da banda termal (L $\mathrm{L} 6)$ com a emissividade de superfície $(\varepsilon)$, dada da seguinte forma:

$$
\operatorname{Tas}=\frac{K 2}{\ln \left(\left(\frac{\varepsilon K 1}{L \lambda 6}\right)+1\right)}
$$

onde:

K1 - constante de calibração da banda termal do Landsat 5 TM (K1 $=607,76$ watts $\left./ \mathrm{m}^{2} . \mathrm{sr} . \mu \mathrm{m}\right)$;

K2 - constante de calibração da banda termal do Landsat 5 TM $(K 2=1260,56$ watts $\left./ \mathrm{m}^{2} . \mathrm{sr} . \mu \mathrm{m}\right)$;

$\varepsilon$ - emissividade de superfície;

L $\lambda 6$ - radiância espectral da banda termal. 
A Tas encontrada é convertida em graus Celsius através da subtração dos valores obtidos por 273,15. Por fim, com base nos procedimentos descritos, foram criados os mapas de uso e ocupação do solo para as décadas de 1990 e 2000, assim como os mapas de Tas. A partir de então, o cruzamento dos diferentes mapas gerados permitem inferir a respeito da influência das diferentes coberturas de superfície sobre os microclimas, assim como a evolução desta dinâmica ao longo das duas décadas estudadas.

\section{RESULTADOS E DISCUSSÃO}

\subsection{USO E OCUPAÇÃO DO SOLO}

Entre as décadas de 1990 e 2000, a Bacia do Rio Tavares sofreu um considerável avanço da urbanização, visível através das alterações espaciais do uso e ocupação do solo ao longo dos diferentes setores da bacia. Com a análise das imagens de satélite foram propostas e identificadas cinco categorias principais de uso e ocupação dentro dos limites da bacia hidrográfica que se mostraram mais relevantes para o objetivo do estudo. São elas: área urbana; vegetação de Mata Atlântica; manguezal; solo exposto ou vegetação rasteira; e corpos hídricos (Figura 3).

No período da década de 1990 a área compreendida pela área urbana, englobando habitações, comércio e demais serviços, detinha um total aproximado de $9,17 \mathrm{~km}^{2}$ (Tabela 2), distribuídos principalmente nos trechos leste e oeste da bacia. A década seguinte apresentou um aumento de mais de 4 $\mathrm{km}^{2}$, ocorrendo um aumento na contribuição de 18,35\% para $27,39 \%$ da área total da bacia
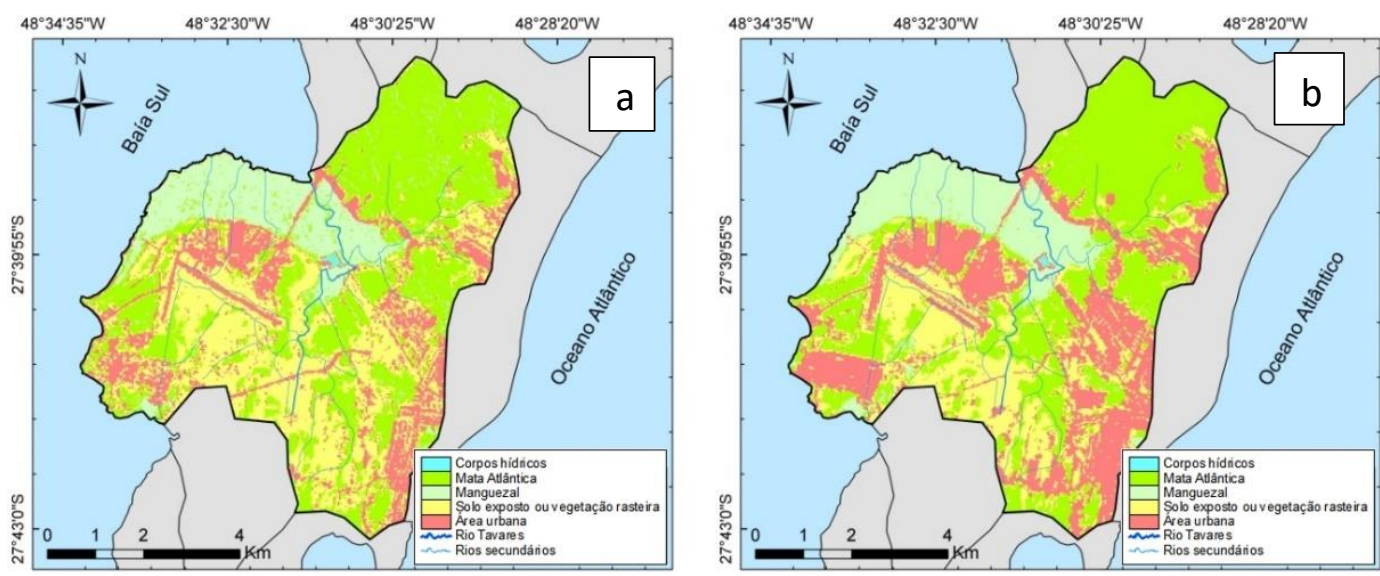

Figura 3 - Mapas de uso e ocupação do solo para a Bacia Hidrográfica do Rio Tavares: a) Média da década de 1990; b) Média da década de 2000

Por outro lado, a área composta por solo exposto ou vegetação rasteira diminuiu cerca de $3,8 \mathrm{~km}^{2}$ até o último período analisado. Possivelmente relacionado com o aumento da área urbana, uma vez que o avanço urbano se deu, predominantemente, por sobre as áreas de solo exposto. Nesse sentido, excluindo aquelas superfícies que possuem características naturalmente expostas, como dunas, faixas de areia e de baixa e esparsa vegetação, tais áreas se mostram bastante favoráveis ao uso imobiliário e demais construções urbanas, sendo alvos fáceis para a antropização. 
Tabela 2 - Extensão das classes de uso e cobertura do solo na Bacia do Rio Tavares, para as décadas de 1990 e 2000.

\begin{tabular}{ccccc}
\hline \multirow{2}{*}{ Classe } & \multicolumn{2}{c}{ Área } & $\left(\mathbf{k m}^{\mathbf{2}}\right)$ & \multicolumn{2}{c}{ Porcentagem em relação à bacia (\%) } \\
& $\mathbf{1 9 9 0}$ & $\mathbf{2 0 0 0}$ & $\mathbf{1 9 9 0}$ & $\mathbf{2 0 0 0}$ \\
\hline Solo exposto ou vegetação rasteira & 14,80 & 11,00 & 29,61 & 22,01 \\
Mata Atlântica & 18,92 & 18,22 & 37,86 & 36,46 \\
Área urbana & 9,17 & 13,69 & 18,35 & 27,39 \\
Manguezal & 7,00 & 7,00 & 14,00 & 14,00 \\
Corpos hídricos & 0,08 & 0,06 & 0,16 & 0,12 \\
\hline
\end{tabular}

Em relação à vegetação de Mata Atlântica, a categoria contemplava uma área de $18,92 \mathrm{~km}^{2}$ durante a primeira década de estudo, diminuindo para 18,22 $\mathrm{km}^{2}$ na década seguinte. A porcentagem relativa à área da bacia passou de $37,86 \%$ para $36,46 \%$.

Se for considerado a posição geográfica do manguezal do Rio Tavares, situado em zona limite com a ocupação urbana de considerável densidade e crescente desenvolvimento, a sua situação aparentemente intacta em relação à área ocupada na bacia demonstra um dado interessante, uma vez que, além destas condições iniciais, os manguezais são considerados sistemas de alta fragilidade. No entanto, é necessário levar em consideração a criação da Reserva Extrativista Marinha de Pirajubaé em 1992, que abrange a região do manguezal, que contribui para a conservação desse ambiente face às forçantes antrópicas externas, além de garantir o desenvolvimento socioeconômico das comunidades tradicionais exploradoras de seus recursos (ESPINOZA; ROSA, 2009).

Por último, os corpos hídricos detectados pelo estudo mostraram uma diminuição na área abrangida de $0,08 \mathrm{~km}^{2}$ para 0,06 km², podendo estar relacionada ao avanço da urbanização e diminuição da área de Mata Atlântica, influenciando nos processos de assoreamento dos corpos hídricos. No entanto, cabe ressaltar que essa diferença pode estar também associada a anomalias na precipitação média anual, resultando em uma diferença de nível dos corpos d'água entre as duas décadas (o que não foi foco de análise no presente estudo).

De forma geral, a cidade de Florianópolis se caracteriza por um processo de urbanização intenso desde o início do "boom" imobiliário na década de 1990 até os dias atuais. A insistência midiática propagada pelo setor turístico e imobiliário, projetando nacionalmente a cidade como um "paraíso natural", é um dos grandes responsáveis pelas alterações espaciais do território nesse período (POZZO; VIDAL, 2011).

\subsection{TEMPERATURA APARENTE DE SUPERFÍCIE (TAS)}

A partir da análise da Figura 4, observa-se uma alta heterogeneidade na variação espacial da Tas para ambas as décadas, estando relacionada à dinâmica de distribuição do uso e cobertura do solo mostrada no mapa da Figura 3. 

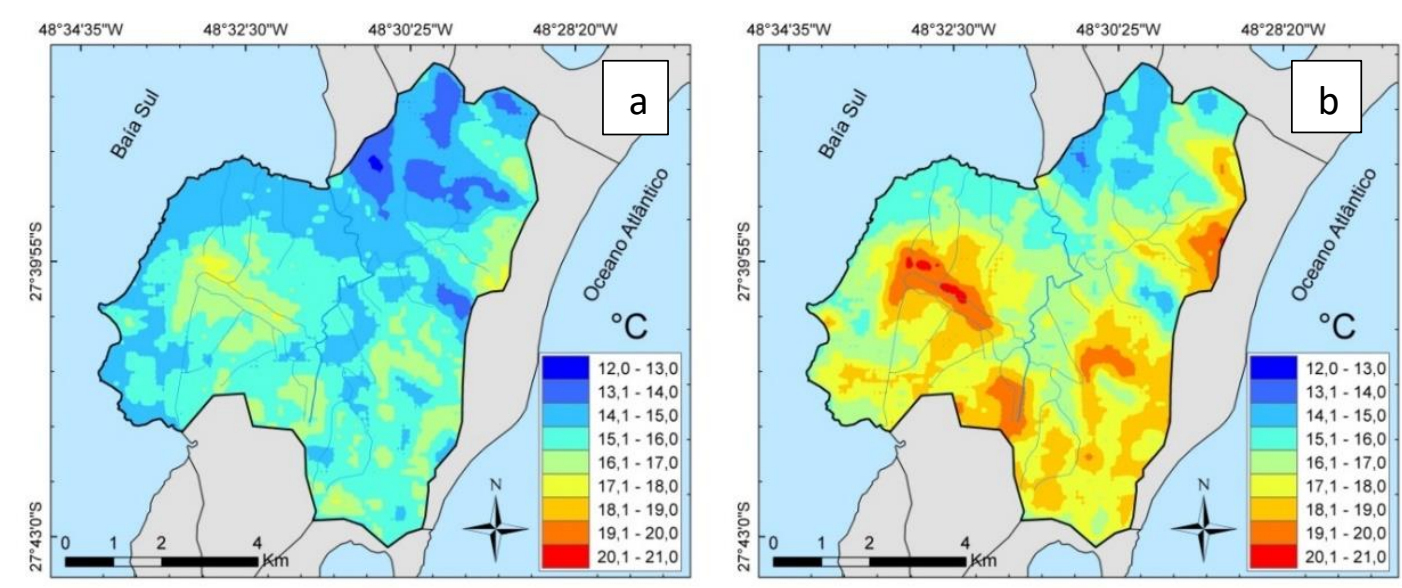

Figura 4 - Mapas de Tas $\left({ }^{\circ} \mathrm{C}\right)$ para a Bacia Hidrográfica do Rio Tavares durante o período de inverno: a) Década de 1990; b) Década de 2000.

Durante a década de 1990, a $T_{\text {as }}$ mínima atinge um valor de $12,5^{\circ} \mathrm{C}$, enquanto que a máxima chega a $17,2^{\circ} \mathrm{C}$. A diferença entre o maior e menor valor de Tas encontrado ao longo da região da bacia é de cerca de $4,7^{\circ} \mathrm{C}$, enquanto que para a década de 2000 essa diferença é de $6,8^{\circ} \mathrm{C}$, com valores variando entre $13,9^{\circ} \mathrm{C}$ e $20,7^{\circ} \mathrm{C}$. Maiores detalhes em relação às estatísticas descritivas em relação aos dados de temperatura para ambas as décadas se encontram na Tabela 3.

As temperaturas mais elevadas se mostraram associadas às áreas urbanas e àquelas de solo exposto ou vegetação rasteira. Esse fato ocorre, pois o solo exposto, na ausência de cobertura vegetal, é caracterizado por uma alta amplitude térmica, podendo variar significativamente sua temperatura em um curto período de tempo (MASHIKI, 2012). Dessa forma, quando a superfície se encontra em períodos de alta exposição solar, sua temperatura tende a aumentar bruscamente, intensificando o processo de irradiação de calor para o meio.

Tanto para a década de 1990 quanto para a de 2000, os maiores valores de Tas encontrados na setor centro-oeste da bacia estão associados à presença do Aeroporto Internacional de Florianópolis, possivelmente relacionados à extensa área de solo exposto e vegetação rasteira, em um terreno bastante aplainado e aberto em decorrência da presença das pistas de pouso. As características físicas destas pistas, pavimentadas com concreto, as tornam consideráveis absorvedoras e irradiadoras de calor para o ambiente. Um outro fator que pode ter influenciado nas características do microclima da área foi a presença de aglomeração urbana devido ao bairro Carianos, vizinho aos estabelecimentos do aeroporto. Segundo Christen e Vogt (2004), áreas de maior concentração urbana apresentam maior capacidade em absorver energia solar na forma de calor, se comparado com zonas rurais próximas, devido principalmente às características dos materiais nas construções (concreto, asfalto, telhas e materiais com alta capacidade de absorção de calor) e à distribuição e presença da vegetação.

Em relação aos valores mínimos de Tas, estes se relacionam majoritariamente com os fragmentos de Mata Atlântica espalhados pelo 
território da bacia, principalmente ao norte e nordeste da bacia. No divisor principal da bacia a altitude apresenta valores superiores ao restante do seu território, atingindo aproximadamente 500 metros no seus pontos mais altos, favorecendo as baixas temperaturas e que estão associadas também à maior taxa de evapotranspiração e capacidade de sombreamento da vegetação.

Dessa forma, a vegetação desempenha um importante papel sobre os microclimas do meio do qual faz parte. Na superfície foliar das plantas, uma parcela da radiação solar incidente é absorvida pela planta para a realização da fotossíntese, enquanto outra parcela é refletida de volta à atmosfera, resultando na diminuição da energia térmica que atinge a superfície e favorecendo a atenuação do aquecimento superficial (MASHIKI, 2012).

Tabela 3 - Estatística descritiva da Tas $\left({ }^{\circ} \mathrm{C}\right)$ para as décadas de 1990 e 2000.

\begin{tabular}{cccccc}
\hline Parâmetro & Década & Mínimo & Máximo & (Máx - Mín) & Média \\
\hline \multirow{2}{*}{ Temperatura aparente de superfície $\left({ }^{\circ} \mathbf{C}\right)$} & $\mathbf{1 9 9 0}$ & 12,5 & 17,2 & 4,7 & 15,4 \\
& $\mathbf{2 0 0 0}$ & 13,9 & 20,7 & 6,8 & 17,2 \\
\hline
\end{tabular}

Por fim, durante a década de 2000, há uma expansão espacial das áreas de maior temperatura em relação à década anterior, em função do avanço da urbanização, do crescimento populacional e a consequente modificação do uso e ocupação do solo.

As áreas dos principais bairros em desenvolvimento na bacia se associam àquelas áreas de maior Tas e apresentam um aumento de até $4^{\circ} \mathrm{C}$ em relação à situação da década de 1990, conforme pode ser notado na Figura 5, que representa a diferença de Tas entre as duas décadas. Os trechos que menos sofreram alterações na Tas ao longo do período de estudo foram aquelas relacionadas às áreas de vegetação de Mata Atlântica e manguezal, apresentando um aumento aproximado de $0,1^{\circ} \mathrm{C}$ a $1,5^{\circ} \mathrm{C}$. No entanto, houve também pontos específicos localizados no extremo norte-nordeste da bacia, região de maior presença da Mata Atlântica, onde a Tas diminuiu até cerca de $0,4^{\circ} \mathrm{C}$ em relação à primeira década. 


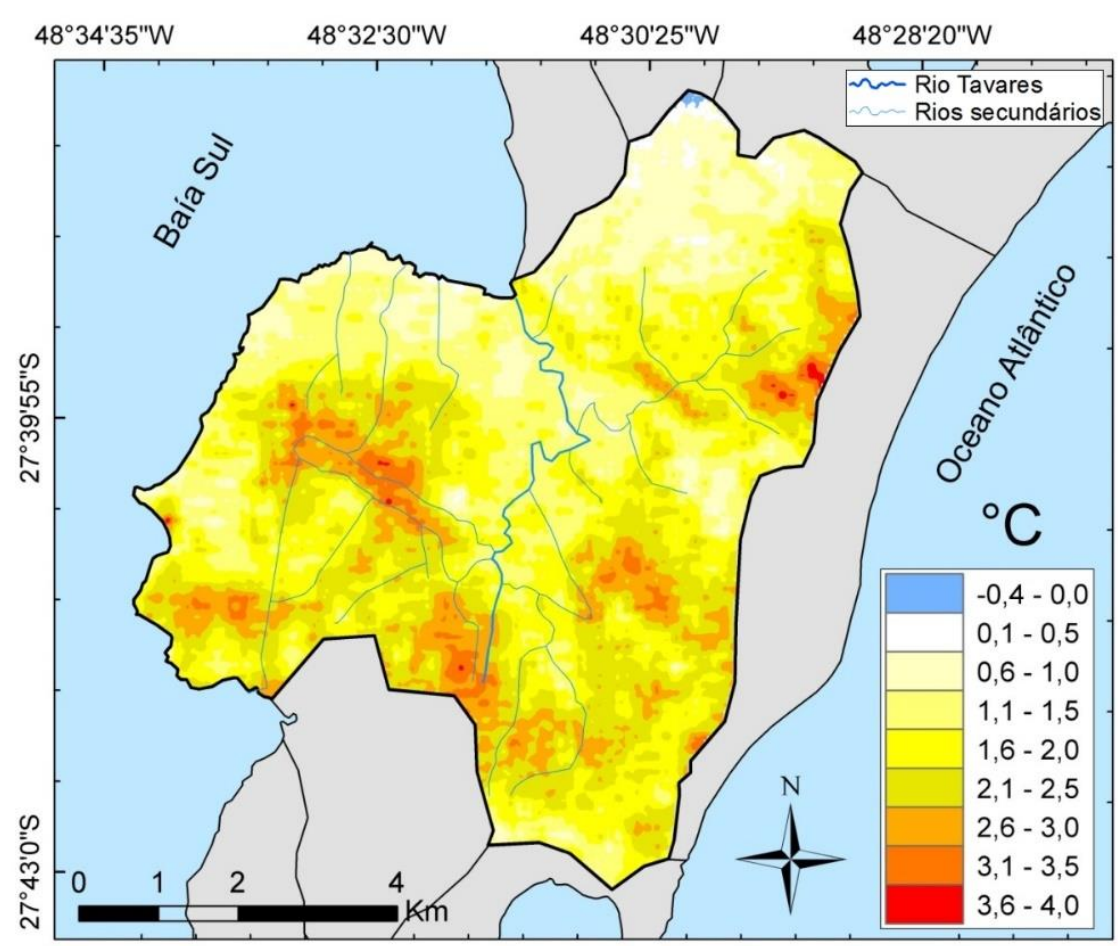

Figura 5 - Mapa da diferença de Tas $\left({ }^{\circ} \mathrm{C}\right)$ entre a década de 2000 e 1990 para a Bacia Hidrográfica do Rio Tavares durante o período de inverno.

\section{CONCLUSÕES}

Ao longo das décadas de 1990 e 2000, a Bacia Hidrográfica do Rio Tavares apresentou uma diminuição de 3,7\%, 26\%, e 25\% nas áreas abrangidas pelas classes de Mata Atlântica, solo exposto ou vegetação rasteira e corpos hídricos, respectivamente, enquanto que houve um aumento de $49,3 \%$ da área urbana. Apesar disso, a classe de manguezal permaneceu aparentemente inalterada.

O estudo permitiu demonstrar que as áreas que apresentam maior Tas estão associadas à urbanização e ausência de vegetação expressiva. Os maiores valores de Tas ocorrem em zonas de bairros onde a concentração urbana é considerável, demonstrando a influência das características dos materiais que recobrem a superfície no balanço de calor do meio.

As Tas mínimas ocorreram nas áreas de Mata Atlântica, com fragmentos dispersos sobre todo o território da bacia, mas principalmente sobre as regiões situadas entre 100 e 500 metros de altitude e sobre os manguezais. Nessas áreas é ausente ou muito pequena a presença de construções urbanas em grande densidade.

Os processos e variáveis que envolvem a caracterização do clima urbano são complexos e necessitam ainda de maior aprofundamento científico, no entanto, alguns dos principais fatores condicionantes da temperatura de superfície puderam ser colocados em questão no presente estudo. A presença e a extensão de áreas verdes, tanto como vegetação nativa, áreas destinadas a 
preservação ambiental ou bosques urbanos; a extensão de superfícies com solo exposto ou vegetação rasteira; as características topográficas; assim como as características estruturais e espaciais das manchas urbanas sobre a bacia se mostram fundamentais no estabelecimento das características térmicas e climáticas da região.

Por fim, as informações levantadas a respeito da temperatura de superfície pelas técnicas de sensoriamento remoto, utilizando o canal infravermelho termal do Landsat $5 \mathrm{TM}$, permitiram a visualização e a compreensão da dinâmica microclimática na Bacia Hidrográfica do Rio Tavares ao longo do período estudado, assim como da sua relação com o uso e ocupação do solo sobre o território, podendo compreender um instrumento útil na implementação de medidas e diretrizes ao planejamento urbano e ambiental e, de maneira geral, ao uso adequado do espaço geográfico a curto e longo prazo..

Essa mudança de visão voltada unicamente ao tópico da redução das emissões dos gases de efeito estufa se refletiu nas pesquisas científicas, caso observado pela análise bibliométrica, já apresentada pelo $5^{\circ}$ relatório científico do IPCC, em 2014, e analisado por meio de uma revista específica nesse artigo. Foi possível observar com a análise da revista Mitigation and Adaptation Strategies for Global Chang, entre os períodos de 1999-2003 e 2009-2013, a evolução das pesquisas em adaptação, em paralelo às de mitigação, tendo maior destaque no segundo período abordado do que havia no primeiro.

Enquanto no primeiro período as pesquisas em adaptação tinham pouco destaque na revista, as pesquisas em mitigação já avançavam em ritmo maior. Nesse período, as pesquisas sobre adaptação davam maior destaque à questão dos impactos possíveis para a agropecuária, assim como aos aspectos conceituais e sociais, denotando início para os estudos desse campo que careciam de base científica para, posteriormente, avançarem em outros temas.

No segundo período os temas principais abordados se modificaram, dando cada vez maior destaque às questões de governança, tendo caráter político e de financiamento, já que a base científica já havia sido mais bem explorada e agora havia necessidade de se definirem os acordos internacionais para se incentivar as medidas adaptativas e como financiar tais medidas.

Sendo assim, pode-se considerar que a preocupação com os efeitos das mudanças climáticas nos territórios dos países no curto prazo passou a ser uma preocupação real em todo o globo, estimulando o avanço das pesquisas científicas sobre a adaptação contra esses efeitos. Há, atualmente, maior percepção de que o risco é iminente, principalmente para vários países em desenvolvimento, que carecem de infraestrutura e condições financeiras e técnicas para prevenir contra esses eventos; no entanto, alguns percalços ainda persistem, principalmente no que se refere ao apoio (financeiro e técnico) dado pelos países desenvolvidos para esses países emergentes, passando pela questão da responsabilização pelas mudanças do clima.

Em relação às pesquisas, foi observada a relevância das parcerias internacionais para o desenvolvimento de pesquisas nos países em desenvolvimento, com metade das publicações de estudos de caso realizadas graças a esses acordos e financiamentos externos, ou seja: os países não centrais carecem de recursos próprios e o financiamento externo proveniente de instituições de pesquisa, organizações internacionais, ou mesmo de empresas 
privadas, é cada vez mais crucial para o desenvolvimento da capacidade adaptativa nesses países.

Por fim, há de se destacar que, embora a questão da adaptação tenha emergido na década passada, não se devem deixar de lado as ações de mitigação tomadas até então, pois as duas questões devem ser trabalhadas em conjunto, havendo medidas preventivas no período atual, mas sem perder o controle das emissões de gases de efeito estufa, que contribui para frear o aquecimento global futuro e, consequentemente, faz com que haja menor necessidade de se adaptar em longo prazo. Nesse sentido, Grasso (2010) afirma que mitigação e adaptação estão inevitavelmente correlacionadas e integrá-las nos processos de tomada de decisão é muito útil para se produzir diversos benefícios e soluções "win-win", não apenas no âmbito da política.

Além disso, conforme Ojima (2009), muitas vezes no planejamento de investimentos de médio e longo prazo, principalmente em infraestrutura, considerar as projeções de mudanças ambientais globais hoje tem um custo muito pequeno se comparado aos custos de remediação, o que se tornou 0 pensamento em voga nas discussões entre os países desenvolvidos.

\section{REFERÊNCIAS BIBLIOGRÁFICAS}

ALLEN, R; TASUMI, M.; TREZZA, R. Satellite-based energy balance for mapping evapotranspiration with internalized calibration (METRIC)-model. Journal of Irrigation and Drainage Engineering, v. 133, p. 380-394, 2007.

AMORIM, M. C. C. T. O Clima Urbano de Presidente Prudente/SP. 2000. 322 f. Tese (Doutorado em Geografia Física) - Faculdade de Filosofia, Letras e Ciências Humanas, Universidade de São Paulo, São Paulo. 2000.

ANDRADE, S. F. Estudo de estratégias bioclimáticas no clima de Florianópolis. 1996. 135 f. Dissertação (Mestrado em Engenharia de Produção) - Universidade Federal de Santa Catarina, Florianópolis, 1996.

ARAUJO, N. B. Contribuição ao estudo da qualidade da água da Bacia Hidrográfica do Rio Tavares: poluição orgânica, Florianópolis, Santa Catarina. 1993. 125 f. Dissertação (Mestrado em Geografia) - Universidade Federal de Santa Catarina, Florianópolis, 1993.

CARLSON, T. N.; AUGUSTINE, J. A.; BOLAND, F. E. Potential application of satellite temperature measurements in the analysis of land use over urban areas. Bulletin of the American Meteorological Society, v. 58, p. 1301-1303, 1977.

CHANDER, G.; MARKHAM, B. L.; HELDER, D. L. Summary of current radiometric calibration coefficients for Landsat MSS, TM, ETM+, and EO-1 ALI sensors. Remote Sensing of Environment, v.113, n. 5, p. 893-903, 2009.

CHRISTEN, A.; VOGT, R. Energy and radiation balance of a Central European city. International Journal of Climatology, Chichester, v. 24, p. 1395-1421, 2004.

DASH, P.; GOTTSCHE, F.S.; OLESEM, F.S.H.; FISCHER, H. Land surface temperature and emissivity estimation from passive sensor data: theory and 
practice-current trends. International Journal of Remote Sensing, Bethesda, v. 23, n. 13, p. 2563-2594, 2002.

ESPINOZA, H. C. F.; ROSA, M. M. P. T. Evolução temporal da cobertura vegetal do manguezal do rio Tavares (Florianópolis-SC) empregando técnicas de sensoriamento remoto. In: XIV Simpósio Brasileiro de Sensoriamento Remoto. INPE, Natal, p. 2705-2712, 2009.

GOULART, S. V. G. Dados climáticos para avaliação de desempenho térmico de edificações em Florianópolis. 1993. Dissertação (Mestrado em Engenharia Civil) - Universidade Federal de Santa Catarina, 1993.

GOUVÊA, M. L. Cenários de Impacto das Propriedades da Superfície sobre o Conforto Térmico Humano na Cidade de São Paulo. 2007. Dissertação (Mestrado em Ciências Atmosféricas) - Universidade de São Paulo, São Pulo, 2007.

HORN FILHO, N. O. Ilha de Santa Satarina. In: Muehe, d. (ed.) Erosão e progradação do litoral brasileiro, 2006.

HUETE, A. R. A soil adjusted vegetation index (SAVI). Remote Sensing of Environment, Oxford, v.25, p. 295-309, 1988.

JENSEN, J. R. Sensoriamento Remoto do Ambiente: uma perspectiva em recursos terrestres. 2ed. São José dos Campos: Parêntese, 2009, 604 p.

KALNAY, E.; CAI, M. Impact of urbanization and land-use change on climate. Nature, London, v. 423, n. 29, p. 528-531, 2003.

KÖPPEN, W. Climatologia: com um estúdio de los climas de la tierra. México: Fondo de Cultura Económica, 1948.

LIMA, V; AMORIM, M. C. C. T. A utilização de cartas de temperatura da superfície na análise de qualidade ambiental urbana. Fortaleza: IX Simpósio Brasileiro de Climatologia Geográfica. Climatologia e Gestão do Território, 2010.

LOMBARDO, M. A. Ilhas de Calor nas Metrópoles: o exemplo de São Paulo. São Paulo: Hucitec, 1985. 244 p.

LUCENA, A. J.; ROTUNNO FILHO, O. C.; FRANÇA, J. R. A.; PERES, L. F.; XAVIER, L. N. R. Urban climate and clues of heat island events in the metropolitan area of Rio de Janeiro. Theoretical and Applied Climatology, v. 111, p. 497-511, 2013.

MASHIKI, M. Y. Geoprocessamento na identificação de ilhas de calor e infuência do uso e ocupação do solo na temperatura aparente da superfície no município de Botucatu/SP. 2012. Dissertação (Mestrado em Agronomia) - Faculdade de Ciências Agronômicas, Universidade Estadual de São Paulo, Botucatu, 2012.

MATSON, M.; MCCLAIN, E. P.; MCGINNIS, D. F.; PRITCHARD, J. A. Satellite Detection of urban heat islands. Monthly Weather Review, v. 106, p. 1725-1734, 1978.

MENDONÇA, M. A dinâmica têmporo-espacial do clima subtropical na região conurbada de Florianópolis/SC. 2002. 343 f. Tese (Doutorado em Geografia). Faculdade de Filosofia, Letras e Ciências Humanas, Universidade Estadual de São Paulo, São Paulo, 2002. 
MONTEIRO, M. A. Avaliação das condições atmosféricas de Florianópolis para controle da qualidade do ar. 1992. 116 f. Monografia (Bacharelado em Geografia). Universidade Federal de Santa Catarina, Florianópolis 1992.

MONTEIRO, M. A.; FURTADO, M. S. O clima do trecho Florianópolis - Porto Alegre: uma abordagem dinâmica. Geosul, v. 19, p. 117-133, 1995.

MOREIRA, E. B. M. Variação espacial e multitemporal das temperaturas da superfície na cidade do Recife. 2009. 96 f. Dissertação (Mestrado em Geografia). Universidade Federal de Pernambuco, Recife, 2009.

ORTIZ, G. F.; AMORIM, M. C. C. T. Ilhas de calor em Cândido Mota/SP: algumas considerações. Revista Formação Online, Presidente Prudente, v. 1, p. 238-257, 2012

POZZO, R. R.; VIDALI, L. M. A cidade contra a ilha: aspectos da urbanização contemporânea em Florianópolis. In: XII Simpósio Nacional de Geografia Urbana, UFMG, Belo Horizonte, 2011.

PRIMAVESI, O.; ARZABE, C.; PEDREIRA, M. S. Mudanças climáticas: visão tropical integrada das causas, dos impactos e de possíveis soluções para ambientes rurais ou urbanos. São Carlos: Embrapa Pecuária Sudeste, 2007.

RAO, P. K. Remote sensing of urban "heat islands" from an environmental satellite. Bulletin of the American Meteorological Society, Boston, v. 53, p. 647648, 1972.

RIOS, N.; CORRÊA, M. P.; TARGINO, A. C. L. Utilização de sensoriamento remoto em análises de albedo e temperatura de superfície em Londrina PR: contribuições para estudos de ilha de calor urbano. Revista Brasileira de Meteorologia, v. 29, p. 537-550, 2014.

ROTH, M.; OKE, T. R.; EMERY, W. J. Satellite-derived urban heat island from three coastal cities and the utilization of such data in urban climatology. International Journal of Remote Sensing, v. 10, p. 1699-1720, 1989.

SCHETTINI, C. A. F.; PEREIRA, F., SPILLERE, L. Caracterização Oceanográfica e Biogeoquímica dos Estuários dos Rios Tavares e Defuntos - RESEX Pirajubaé, Florianópolis, SC. Brazilian Journal of Aquatic Science and Technology, Itajaí, p. 11-28, 2000.

SILVA DIAS, M. A. F.; DIAS, J.; CARVALHO, L. M .V; FREITAS, E. D.; SILVA DIAS, P. L. Changes in extreme daily rainfall for São Paulo, Brazil. Climatic Change, v. 116, p. 705-722, 2013.

SOUZA, J. D.; SILVA, B. B. Correção atmosférica para temperatura da superfície obtida com imagem TM: Landsat 5. Revista Brasileira de Geofísica, São Paulo, v.23, n. 4, p. 349-358, 2005.

TREVISAN, A. B.; SANTOS, V.; LUIZ, K. S. Estimativas de ganhos ambientais para a Bacia Hidrográfica do Rio Tavares a partir da implantação do sistema de coleta e tratamento de esgotos na região. Bento Gonçalves: XX Simpósio Brasileiro de Recursos Hídricos, 2013.

WENG, Q.; YANG, S. Managing the advers thermal effects of urban development in a densely populated Chinese city. Journal of Environmental Management, Oxford, v. 70, n. 2, p. 145-156, 2004. 
YANG, X.; ZHANG, Y.; LIU, L.; ZHANG, W.; DING, M.; WANG, Z. Sensitivity of surface air temperature change to land use/cover types in China. Science in China (Earth Sciences), v. 52, p. 1207-1215, 2009. 